\title{
Improvisation and Global Sites of Difference: Ten Parables Verging on a Theory
}

\author{
Daniel Fischlin and Eric Porter
}

in memoriam Cedric J. Robinson

I

\begin{abstract}
We might take improvisation to denote that semi-transparent, multistaged, multi-leveled process through which we sense, perceive, think, decide, and act in real time. But this notion then encompasses such a broad range of behaviors that it becomes difficult to draw a boundary around it, let alone to definitively prove its presence or absence in a given situation. We cannot "know" whether an action is improvised just by observing it in a vacuum. What we seem to be doing, instead of precisely identifying improvisation according to some intrinsic attribute, is allowing cultural and contextual factors to regulate its presence or absence. That is, we "perceive" improvisation only through systems of difference. - Vijay lyer
\end{abstract}

Think of a stream without source and of infinite variety constantly flowing, not always unimpeded, not always in any one direction.

Over the contours of irregularly shaped stones in the riverbed, round fallen trees, here more shallow, there deeper than you imagine; different speeds, sometimes congruent, sometimes wildly chaotic. Calm where you least expect it.

You dip your hand into the stream for a moment. Any moment will do.

Cup your palm and bring up some water. Where the stream is shallow, water is harder to grasp. Where the stream deepens, the water is for some reason sweeter-colder too. And on it goes in permutations too vast to calculate. Many hands will dip into this stream at many spots along its journey.

The stream makes incalculable sounds too: symphonic in places, no more than the click of pebbles in others. An underlying surge is always present, even where the stream is most silent.

The length of this stream without end, source of infinite possibilities, defies description, except to say that it constantly figures and re-figures the potential carried by the running water. Flow happens constantly even when interrupted or unheeded - it is always already in place in the constancy of its movement.

No two sounds it produces are necessarily alike or reproduce-able, except in that one spot and one moment when the stream is as it is. Where you are along the stream, in the stream, determines what you will hear, and what will sound. Wind, heat, rain, erosion, birds, insects, passers-by-all change the soundscape in unexpected permutations.

Anyone who comes across the stream, regardless of who they are or where they have come from, can stand by and observe its contours in that spot-or bring its waters to their lips, or simply listen. The stream constantly produces this variety, this difference that is its lifeblood.

This extended metaphor might seem to describe improvisation as a "system of difference," a blend of contextual specificities, an experience of disparate possibilities, but we double back and dispute the notion that difference can be systematized. We need systems that tend toward pluriversality, not monocultures.

The Korean Pansori singer II-Dong Bae's vocal practice conforms to deeply traditional narrative and shamanic musical forms, but also encompasses free improvisation and creative musicking. 


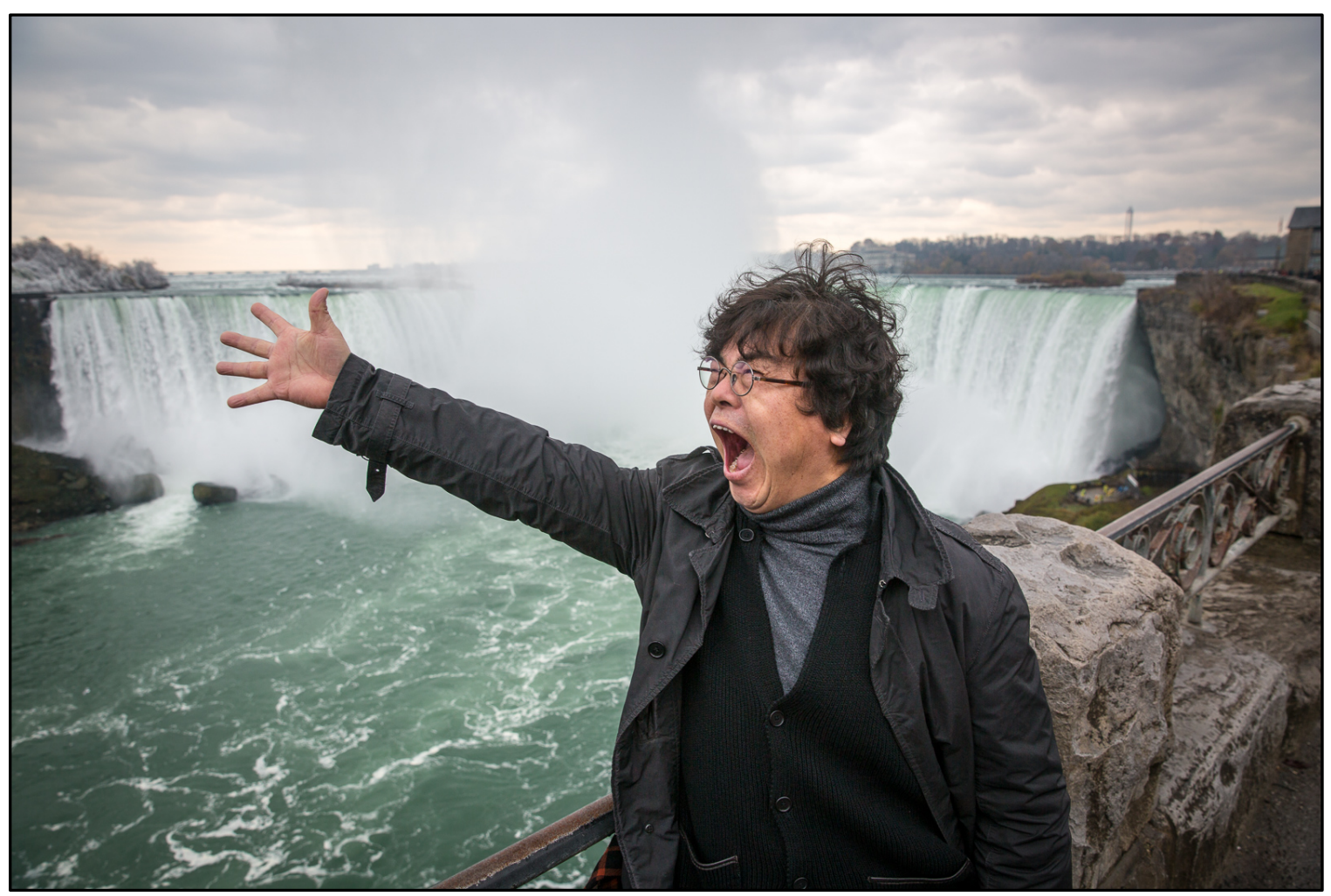

Pansori singer II-Dong Bae in full voice at Niagara Falls (2014). Photo courtesy of Dong-Won Kim.

His vocal technique and musical practice evolved over years spent by a waterfall honing his craft. The source of his sound traverses the waterfall, and any listener who hears him also hears the ghost of the cascade and the flow of which it is a part.

Pianist and improviser Vijay lyer says, "We hear the sources of the sound, and we've evolved to identify them" (qtd. in Wilkinson). Contexts that are here and now travel back to distinctive sources, sites of difference from which sound carries. Hauntologies - traces of sounds that once were-are to be found in improvisations, in part, as a means for articulating the memory of these traces.

Sound and affect must be embodied, lived in the moment that takes us elsewhere.

When "entering African-American music 'and trying to figure out what my position is and striving for some place within it,' Iyer [says], his status 'has frequently been called into question.' Since childhood, he has been aware of his racial identity - of being, as he has said, neither white nor black, and having a different sounding name" (Wilkinson; our emphasis).

Neither/nor is a site in this context; in another context, something wholly different, another identity, a calling into question of position, an embodied cognition in the real-time flow of improvisation.

Has it really taken this long to understand that body and mind are connected, each a function of the other, inseparable and interconnected?

The thinking-feeling continuum, too, is embodied and cognitive, improvisation a means to explore that spectrum creatively. But these rudimentary concepts only go so far before they run into the remembrances carried in sound-spectres of affect and historicity circumventing presence and absence, reverberating a phantom aesthetics.

Every improvisation is associated with a history of sounds and silences, both chosen and imposed-and these, too, play a role in consciousness, identity, and agency. 
Thinking-feeling with Cedric J. Robinson and his legacy, we stretch to grasp the multitude of these histories while recognizing the foundational resonances of the Black radical tradition manifest in what he describes, pace the work of Richard Wright, as "the syncopations and the phrases, the scamp and the beat, the lyric and melody of Black language, Black beliefs, Black music, sexual and social relations and encounters" and, ultimately, in "the improvisational possibilities obtained in that Black culture's collisions with its own parameters and those prescribed by the market forces and labour demands of capitalism and by a racialist culture" (Black Marxism 449).

The stream has no source, no clear direction, but it does have a common, fluid, resiliently adaptable substance. Improvisation: a strategy to circumvent the expected, the constraints of imposed structure, the monoculture of histories that forget the multitude.

\title{
II
}

\author{
The practice of free improvisation-what I call a "meta-music" guided by \\ creative responses to contingent events and conscious social agency-is \\ where we dispense with what is culturally familiar as music, moving \\ beyond the violence of the new. The compulsion to experiment arises \\ because existing forms are inadequate to express things that concern a \\ world in turmoil, yet the effects and results of experimentation are \\ themselves vulnerable to the cannibalism of capital, fodder even for the \\ postmodern. - Eddie Prévost
}

Improvisatory practices are not any one thing. Even the irreducibility of improvisation is itself too reductive a way of understanding it, a misleading generalization that misses the specificities and differential practices out of which it arises.

Inexpressibility is a condition that inspires improvisation as much as it becomes its end. How do we find, through improvisation, the affect that corresponds to what cannot be uttered?

Inadequacy gives rise to expressive means, nurtures virtuosos defined by limitations, amateurs uplifted by unpredictable possibilities. Aesthetic and political turmoil intermix in a struggle to exceed the accredited bandwidths determined by convention and orthodoxy.

What sounds produce excession-something so far beyond the norm, so far outside knowable and normative contexts that it appears to have been conjured up out of an unthinkable reality? ${ }^{1}$

Each step that dispenses "with what is culturally familiar as music" has to come from somewhere. All sound begins with what is available in the sites where it is played and heard. This is as familiar as it gets. What emerges from the site and context-specific events, no matter how experimental or unorthodox, is nonetheless a product of those players in that moment making sounds with those tools.

AMM guitarist and electro-acoustician Keith Rowe talks about the improvised sounds of a prepared guitar laid flat on a table, a technique he devised to echo Jackson Pollock's break with conventional art practices by abandoning the easel. For Rowe, the electrified sounds he produces using an array of found materials (screwdrivers, springs, battery operated vibrators, foam, etc.), and occasionally radio broadcasts, reflect "something about the world . . . more industrial, more mechanical" ("Guitar"). The geography of objects and the electromagnetic waves deployed in an improvised performance are both unique and determinative-as determinative as the agency of the player navigating this geography.

It takes a Keith Rowe to be a Keith Rowe-through the specificity of embodied cognition made manifest in his improvisations.

The social, critical, historical realities of 1965 (the year the AMM was founded by percussionist Eddie Prévost, saxophonist Lou Gare, and Rowe) also cannot be separated from the excessive sounds produced by the group in reaction to commercial pop music and larger socio-political contexts. 
When asked to "Define the sound you're still looking for or you want to hear," Rowe responds with "a sound that Occupies the Moment, possibly the most vital aspect of Music (anything?) is each note sound event should seek to occupy the moment" ("13 Questions").

Rowe is particular here: "each" note; "each" sound; "each" event-a specific moment that occurs only this once. It happened then in that moment that will never come again. That moment is a site of difference, different from the moment to come, the moment that just was. New particularities arise as improvisers find the means to articulate them.

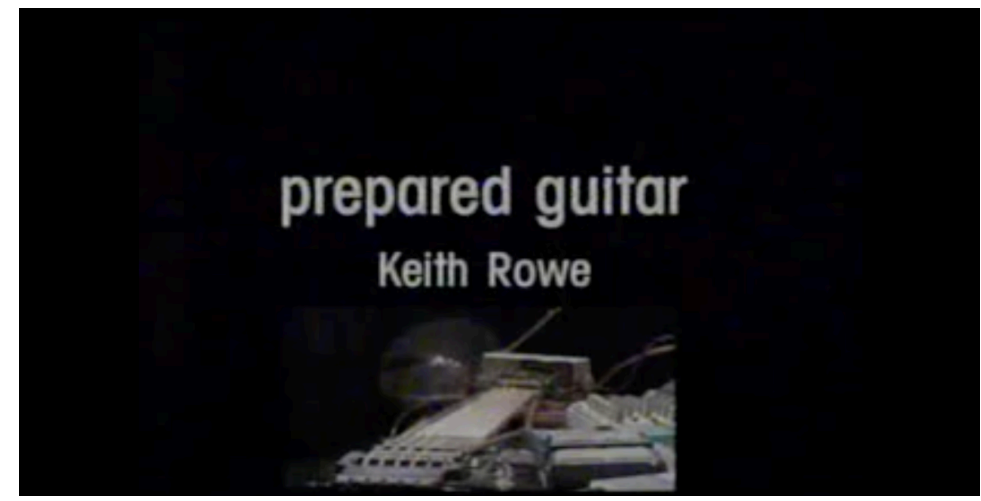

Click the image above to view more on Keith Rowe and footage of him playing prepared guitar.

Improvisation in the moment reminds us of this ephemeral, concatenated reality of specific transitions from one thing to the next. Contingent events and conscious social agency determine sonic realities--frame the specific contexts that lead from play to possibility.

Improvisation: a necessary experimentation with context, but also a specific practice, an awareness of playing the potential and possibility of any moment with the tools at hand.

\title{
III
}

\author{
Greek citizens set out to self-organize the urban landscape through a \\ series of networks, collectives, and community centres, engaged anew in \\ exploring the limits of performance practice within an "im-potential" \\ landscape, building on the possibilities of improvisation and testing \\ interrelations between political and artistic practice(s). Improvisation \\ became simultaneously a mode of action during crisis and a practice of \\ survival. This was accomplished through impromptu artistic and political \\ movements that sought to re-imagine, reclaim, and re-constitute public \\ spaces through community encounters, impromptu street interventions, \\ homemade theatres, and solidarity platforms. - Gigi Argyropoulou
}

In February 2016, Chinese dissident artist Ai Weiwei stirred controversy with a photo of himself face down on a beach on the Greek island of Lesbos, echoing a photo of the drowned Syrian boy, Aylan Kurdi, that shocked the globe in September 2015. The immigrant "crisis" in Europe brought on by the Syrian situation continues, and in 2015 and 2016, much of it transpired in the borderlands of Lesbos (a key transit point for Syrians seeking asylum in Europe), given both its proximity to Turkey and the ready ferry access it provides to mainland Greece. Lesbos is situated at the periphery of Europe, but also at the transcontinental intersection of Western Asia with the Middle East.

Just a few weeks prior to Ai's provocation, Oxfam announced that the 62 richest people on the planet have a net worth equivalent to half of the planet's poorest people, with The Guardian reporting "a trend showing that $1 \%$ of people own more wealth than the other 99\% combined" (Elliott). This number has now been revised in 2017 to suggest that eight billionaires own wealth equivalent to the poorest $50 \%$ of the planet.

Shocking disproportions abound as children die, as they have long died, in borderlands-every child lost the bearer of distinct aural imaginaries and unique sonic potentials. 
Crisis has many names and forms: escape from a brutal civil war, the incessant militarization of responses to geopolitical conflict, the disproportion of a minuscule elite weighed against a majoritarian world where poverty is endemic.

"The clock of 'modern times' is running down," Cedric Robinson told us decades ago. "Not even the brilliant wizardry of high technological achievement can muffle the rumblings from the degenerating mechanism. It is the occasion of opposition and contradiction and the moment of opportunity. That is because the times which mark the dissolutions of civilizations compound the maturations of both internal and external processes" (Black Marxism 450).

The regenerative potential in improvisation thrives in opportunity, turns dissolution and degeneration into creative refiguration. What might it mean to be faced with ending as an improvisation--to improvise an ending, or to end improvising? What might it mean to live in improvised time, in the time of improvisations overtaking crisis?

Gigi Argyropoulou elsewhere discusses the street as a site of improvised responses to crisis:

Thinking of, with, and within the street ... In the past few months [of 2012] streets and squares of countries and cities as diverse as Tunisia, Spain, Greece, Wisconsin, Tehran, Lisbon, Yemen, New York, Mongolia, Egypt, Belarus, Syria, Oman, Bahrain, Libya, Morocco have acted and are doing so in the present as theaters of crisis, change, mobility, visibility, anonymity, rage, desperation, death, and life. The dialectic of resistance and oppression made bare, brought to the world in high definition... These trajectories filled with fluid rivers, single darting figures and standing yet undulating seas of human bodies expressing for us the communication and communion of crisis ... If, as Benjamin writes, we are always in a state of emergency, then we are always also in a state of emergence. And in streets close to home . . I have been attending the improvised people's assembly held in Syntagma Sq. for a few weeks now and I am struck by many thoughts and feelings. First, the visceral nature of one's sensing of the new-where one recognizes it because the malleability and ephemerality of context and convention are made aural and visible, seeing that malleability twisting, never settling before one's eyes, the work itself as it unfolds, the contingency that is the absence of a finished product - the presentness of the moment-and in that presentness-Chistory bearing down with watchful eyes and small smiles ... here is an attempt at "direct democracy" a few hundred meters from whence it first articulated and defined itself more than 2,500 years ago . . . (Argyropoulou and Vourlomis)

Improvisation occurs in these sites-beaches, streets, and squares-as a function of political and cultural realities connected to crisis and instability. It manifests as emergent critiques of site-specific injustice, oppression, massive inequality, indifference, impunity, and neglect.

Improvisation: the readiness to remake things out of crisis-the responsibility to act creatively and in concert with others to reclaim a public commons under attack; not the answer, but the beginnings of site-specific strategies connecting the creative and the critical, embodying a social practice that negotiates stricture and potential.

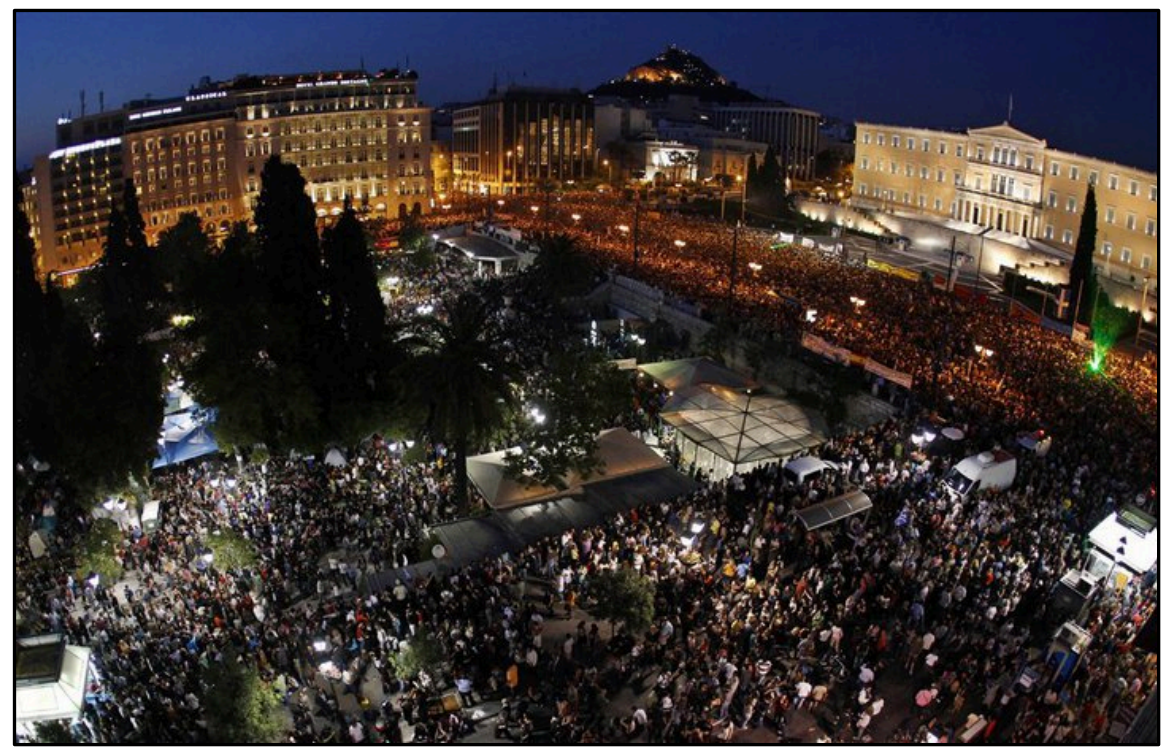

2011 Greek Uprising. Photo by Kostolis at English Wikipedia. 
IV

Each major Chinese city has a unique socio-cultural atmosphere that affects the practice, performance, and reception of alternative music. Beijing is often known as the rock and roll city, Shanghai the jazz city, and Guangzhou and Shenzhen the cities of Cantopop. These cities are also where one finds the most active improvising, experimental, and electroacoustic music scenes in contemporary China. - Jing Wang

How are improvisational practices situated in cities? How do cities situate improvisatory practices?

Improvisational difference in cities across the globe flows from cultural-historical contingencies. There are complex demographic, economic, and social reasons behind urban musical identities, and why major cities draw improvisers and their audiences.

The particularities of improvisational practice emerge not simply from the ways we inhabit cities, but also from their physical characteristics-and then from both the culturally specific manifestations of built environments and their contingent exteriorities.

Manuel DeLanda presents assemblage theory as an alternative to social theory that presupposes "relations of interiority" in which "the component parts [of a social formation] are constituted by the very relations they have to other parts of the whole," often with assumptions about the stability of said components' form and function. Assemblage theory instead emphasizes "relations of exteriority" out of which "the properties of a whole cannot be reduced to those of its parts [because] they are the result not of an aggregation of the components' own properties, but of the actual exercise of their capacities" (9-11).

Improvisers make sounds on horns, guitars, drums, basses, pianos, laptops, voices, "screwdrivers, springs, battery operated vibrators, foam, and the like" (Rowe, "Guitar"). These sounds reflect, bounce, and skip off walls, ceilings, windows, and furniture before escaping into the night air to collide with the street (buildings, pavement, power lines, cars, pedestrians, and so on) and its soundscape. This happens as it will never happen again. A place name (city, culture, neighborhood) cannot describe or define this process. The cityscape is a beehive of uncertainty, tremulous connections, random synergies, and dissonances that defy summary. There is no algorithm for this level of irreducible energies converging and dissipating. Might the same be said for improvisation?

In the words of Brandon Labelle, "A site for the generative mixing and intermixing of disparity and difference, of interference, the street is an acoustical instrument for the propagation and diffusion of multiple sonorities, which the city itself comes to feedback" (130).

When improvisation is part of this mixing and intermixing, does the built environment improvise a response?

Wang quotes Chinese free improviser Li Jianhong: "In environment improvisation, I am not in an equal relation with environmental sounds, and there is no one-on-one dialogue between me and the nature ... environment coexists with my playing as one."

Does sonic coexistence without dialogue mark the limit and the possibility of the street as improvising agent?

The street is full of people improvising on foot, in cars, in conversation. Improvised labor is built into asphalt pours, concrete walls, and lamp posts.

Shen Piji improvises with Emei music frogs (hylarana daunchina). When his group begins to play, the frogs jump into differently shaped ceramic containers "and make sounds with different pitches, volume and intensity": "environment improvisation" with inter-species dialogue? 


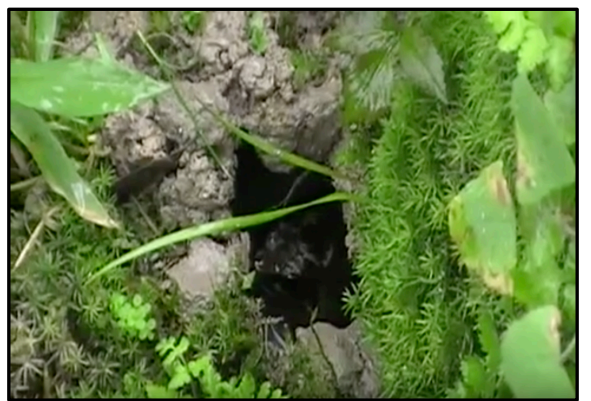

Click the image above to view a recording of an Emei frog in performance.

Emei frog males use vocalizations to announce their presence in underground nests. Their calls intensify when they hear the calls of nearby females. The male's calls resonate from the walls of his burrow, describing its architecture and providing information to the female so she can choose her mate.

V

The paraders strutted, high-stepped, marched in time, and otherwise
danced down the street, a collective movement that also featured
individual creative freedom. The unofficial slogan of the underground
parade, "Keep that lane open," serves to keep the parade hemmed in, lest
the revelry and chaos get "out of control." It provides an improvised,
provisional order that helps stave off police harassment and keeps the
parade from blocking traffic, which would almost surely attract negative
police attention.

Furthermore, it is an act of self-discipline, an aspect of improvisation that often gets left out of discussions of its social meanings, but that improvising musicians like Sun Ra valued ... "Keeping that lane open" is an accommodation to the everyday aspects of the street, leaving space for others to move outside of the parade if they wish. - Peter A. Williams

Should musical improvisation in the street be fleeting, standing (or dancing) in opposition to the site-specific, nonimprovisatory forces of the street, be they legal, bureaucratic, carceral, or simply physical?

The 2012 Kansas City Mardi Gras parade that Williams describes (and danced in) built upon long-developing, improvised urban rituals from New Orleans and other circum-Caribbean cities; rituals that were crafted in part to help people survive the disciplinary aspects of racial states. Ironically, as Williams tells us, it took a $21^{\text {st }}$ century hurricane to re-animate and expand this performative diaspora.

Improvisation unfolds dialectally in relation to power, but it is not as simple as contesting power by improvising in the face of the armature of the state. State power manifests itself through improvisatory and non-improvisatory modes.

Sociologist Harvey Molotch argues that the Katrina disaster was amplified not because the state does not improvise, but because government officials and bureaucrats failed to improvise adequately in this case. Social organizations, he argues, are usually created by people who improvise: "Individuals figure out what to do on an ad hoc basis, mobilizing, elaborating, and finessing the rules as things move along. We are . . 'artful,' and this forms social life, bureaucratic and otherwise." During Katrina, animus toward and distrust of the city's poor, black population was one reason why government workers "fell back on the Weberian default. They became bureaucrats in the formal sense, rather than the bureaucrats who populate much of real life" (31-32).

Keeping the lane open, restricting the scope of improvisation, reining it in, may prevent improvised violence in the form of nightsticks and bullets.

Or prevent a citation for the more well-heeled in the group. 
As middle-class whites improvise dance steps in the multiracial second line, a utopian society is imagined, community is built, and hegemony is preserved. Williams tells us to "keep that [analytical] lane open" to an awareness of such complexity, in Kansas City and elsewhere: "When the group reached the overpass of US Highway 71, a cheer went up and the musicians played louder, taking advantage of the cathedral-like acoustics under the cement and steel structure to amplify their sound."

In New Orleans, second line parades often improvise a stop on North Claiborne Avenue, with the brass band music resonating off the Interstate 10 overpass above-a legacy of federally funded white flight and urban renewal that decimated the business district along this street (as it did in Kansas City neighborhoods).

The reverberating brass (and reed, wood, and skin) sounds mark a communal presence despite it all.

Think about a concrete edifice near where you live or where you have traveled. What would a bass drum beat, the rattle of a snare drum, the notes of a major seventh chord reverberating off it, say about the history of that place? What would they say about its future? What would they say about you in relation to that place?

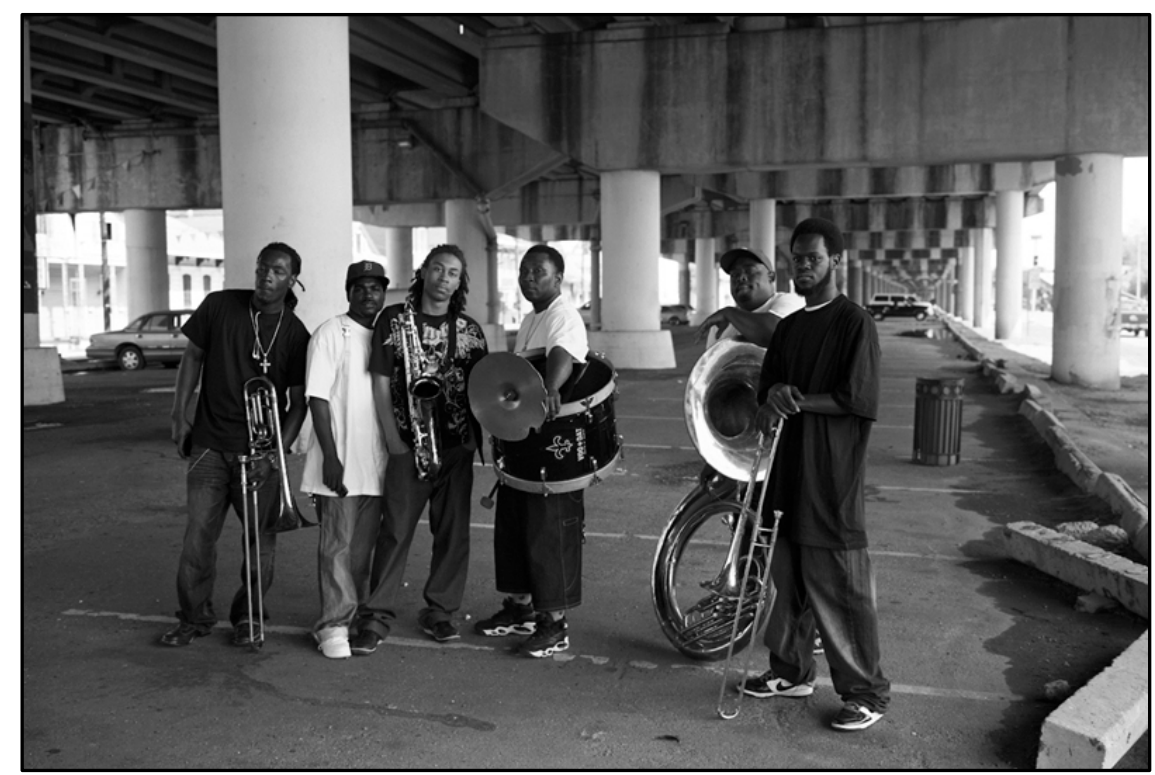

Brass band after playing for a funeral, Claiborne Avenue, New Orleans, 2010. Photograph by Lewis Watts.

VI

In 1982, [critic and jazz historian] Mark Miller suggested a number of reasons why the Canadian jazz scene, most blandly typified in Toronto, has been historically so conservative. Chief among them was the way that an American-dominated music industry tended to filter out alternative voices through disparities in broadcasting and distribution . . . In this context, the Artists' Jazz Band specifically employed improvised performance to situate themselves within the resistant relationship that jazz, especially free jazz, had created for itself in relation to North American culture ... the Toronto jazz community reacted to free jazz in the way any endangered trade would react to an outside threat, by closing ranks against the musical devices, as well as the kinds of resistant, political, and countercultural discourses that arose around the music. - David Neil Lee

On the Edge: Improvisation in Music-Derek Bailey's four-part television documentary series shown on Channel 4 in the UK in 1992-focuses on a multitude of global sites of difference where improvised musicking occurs and also identifies four underlying strategies for addressing diverse improvisatory practices: "passing it on," "movements in time," "a liberating thing," and "nothin' premeditated." 
Pedagogy and historical memory, migratory realities that create new sonic forms, free improvisation and liberatory expressive practices, and spontaneity-the four episodes grouped around these thematics "provide a world-view of the subject, not being bound by country, musical genre or preconception."

The documentary surveys site-specific global improvisatory practices: Douglas Ewart, multi-instrumentalist and former president of the AACM, working with young students at Haynes School in Chinatown, Chicago; Gaelic psalms on the Scottish Isles of Harris and Lewis; Pundit Hanuman Misra; Sufi music in New Delhi; Hindu music in Rajasthan; flamenco; Indian kathak mime and dance; Egyptian gypsies; Max Roach at the Harlem School of the Arts (yet another musical community space offering under-privileged youth access to cultural resources); Sang-Won Park from Korea, playing ajaeng, a zither-like instrument, and singing both traditional Korean and freely improvised music; Nashville; mbira music from Zimbabwe; and music from the Polynesian island of Tonga.

On the Edge only hints at vast practices of site-specific improvisatory sounds, at specific peoples who sound as a function of who and where they are, at a ubiquitous, irreducible variety of sounds and an astonishing reserve of creative practices found all over the planet.

In Toronto, a first-wave of improvisers in the sixties largely drawn from the visual arts milieu reacted to jazz conservatism and established a countercultural beachfront known as the Artists' Jazz Band. Another outbreak of sonic uniqueness occurred in an unexpected context: Canadian culture, dominated by the power and reach of its American neighbour and the ubiquity of American pop culture translating jazz to Canadian musicians, spawned a resistant sonic practice, one that gave rise, in successive generational waves of musicians, to a vibrant improvised music scene distinct from others across the country.

In 1982, a group of independent musicians and producers from Montreal established Ambiances Magnétiques: "a non-profit, Canadian musical collective is formed. The entity emerged out of necessity: the avant-garde tastes of the members - which include jazz, classical, folk, and rock — proved to be too challenging for prospective distributors and commercial record labels. Thus was created Canada's largest and most active label devoted to a variety of improvised musics that include jazz, avant-garde, rock, and unusual hybrids vested in improvisatory practices" ("Ambiances Magnétiques").

Again, the limited space of popular culture and commercial considerations force an outbreak of dissident sound. Again, improvisatory practices are at the heart of the specific sounds produced, the specific cultural practices critiqued via this form of expressive politics. Improvisation does not transcend any of these contexts, but is specific to them, unthinkable without the distinctive voices, histories, and cultural materials that come together to produce how it sounds. Bebop redux!

African American film producer, director, and writer Oscar Devereaux Micheaux (1884-1951) produced some 44 films and is considered the first African American film auteur whose work explicitly focused on race. As Cedric Robinson reminds us, "Micheaux pushed race movies into explicit political critiques of the American national myth. Micheaux's extraordinary performance (particularly in silent films) as a subversive was enabled by his adaptation of rhetorical structures gestated in Black music" (Forgeries of Memory and Meaning xvii).

Music, in the highly racialized contexts Micheaux had to contend with, was a resource for critique, for adaptation, for rhetorical structures of argument and affect that enabled resistant politics and subverted delusory myths that reinforced state self-interest. Again, alternative figurations of identity emerge from music so intricately tied to improvisatory cultural practices of resilience. Bebop anticipated!

As another example, in the differently racialized contexts of Nègres blancs d'Amérique [White Niggers of America] (1968), Pierre Vallières-a key figure in the Québécois separatist movement Front de libération du Québec (FLQ)critiques French colonial practices of settlement in the "New World" that would become Québec and Canada, exposing the exploitative practices of capital and deeply abusive power structures that linked immigrant populations (black and white) in the Americas and brought them to their knees. Vallières's analysis leads inevitably to revolt against these conditions, figured in revolutionary (if not improvisatory) terms: "Un révolutionnaire doit toujours être prêt à recommencer et consenter à vivre continuellement dans le risque. L'activité révolutionnaire n'est jamais de tout repos" [The revolutionary must always be ready to begin again and to consent to live continuously with risk. Revolutionary activity never rests.] (322; our translation).

How can these forces of resistance rest when faced with, for instance, the restrictions the Nazis imposed on jazz dance orchestras in Czechoslovakia during the occupation? 
preference is also to be given to brisk compositions over slow ones (so-called blues); however, the pace must not exceed a certain degree of allegro, commensurate with the Aryan sense of discipline and moderation. On no account will Negroid excesses in tempo (so-called hot jazz) or in solo performances (socalled breaks) be tolerated; strictly prohibited is the use of instruments alien to the German spirit (so-called cowbells, flexatones, brushes, etc.) as well as all mutes which turn the noble sound of wind and brass instruments into a JewishFreemasonic yowl (so-called wa-wa, hat, etc.); (qtd. in Gould; our emphasis)

Aesthetic tyrannies, racist politics, and restrictions on the play of sound unite in destroyer culture, and these authoritarian alignments are directly challenged by improvisatory iterations that ask us to vibrate differently.

Consider the following thoughts by Jean Derome, co-founder of Ambiances Magnétiques-and one of Québec's great musical treasures_of "L'Année Jean Derome" ["The Year of Jean Derome"], a project celebrating his vast creative output and influence on the Québec improvising scene:

it is L'Espoir de ne pas perdre espoir [the hope to not lose hope]; the strong desire to last.

It is Suoni Pourpour il popolo [sounds for the people], ${ }^{2}$ because a nation without music . . . [is] not a nation; because a cultureless country is not a country at all, and it is in order to call ours a country that Nous perçons les oreilles [we pierce ears].

Experiencing Québec's Musique actuelle is to be resourceful, inventive, turbulent.

To create currents ...

To improvise every day, to compose with ... reality, to conduct oneself and ... others as well.

I change the world by making people vibrate. [our emphasis]

Again, music can "compose reality" to forge identity, to provide resources for resilience and self-fashioning. Derome's ideas resonate with a challenge to conservatism, to commercialism, to the ethos of inertia and lack of agency that shape forms of ossified creative expression. Moreover, improvised music links hope and "survivance," a word rooted in Québécois struggles to resist Anglo-American hegemonies and in First Nations battles for presence and resistance against colonial genocide. ${ }^{3}$

Within this resistant, creative ethos, "There is a more fundamental and personal reason for developing skills of dialog and heurism. It is a playful construct form where the improviser, the informal musician, can locate an infinite source of new material. It is an idea of how we can take ourselves beyond the confines, the dictates, the numbing paralysis of conservatism - towards new vistas and soundscapes. This is cognitive fluidity-the seat of creativity?-an albeit intermittent characteristic we have inherited from the struggles of our prehistoric ancestors" (Prévost 277). Tied into this is the notion of wu-wei, effortless non-doing, which Edward Slingerland argues depends on "social interaction and shared values," on "caring," and on performing within social contexts that matter (37). Slingerland cites social psychologist Timothy Wilson and his notion of "the adaptive unconscious to refer to the vast repertoire of implicit skills, habits, and perceptions that allow us to navigate the world effectively, with little, if any, conscious awareness" (36).

Sites of difference provide alternative takes on how others exemplify these forms of adaptive unconsciousness that lead to flow and cognitive fluidity, the capacity to generate creative ideas, structures, forms, and affects-and as Prévost compellingly argues, "We ignore them to our disadvantage" (279). But flow and spontaneity do not arise apart from the contexts in which they occur, and sites of difference express these underlying constructs in ways that differ. Moreover, flow and spontaneity are not the only methodologies that govern improvisation. A stutter may subvert predictable outcomes just as well as a spontaneous overflow, assuming of course that all improvisers persistently deploy the same techniques to produce divergent sounds.

Limiting improvisatory utterances to any one aesthetic or metaphysical strategy is itself a betrayal of the very potential for generative (unpredictable) difference that arises in improvisatory cocreation. The knife's edge improvisation skirts is bound on the one side by the unpredictable élan of creative undertakings in which improvisation is at work, and on the other side by Jacques Derrida's claim about the utter "impossibility of improvisation . . . because he presupposes an 'absoluteness' (in terms of freedom, originality, authenticity, and singularity) of improvisation that is incompatible with the structure of iterability" (Landgraf 33). Iterations arise from multiple sites in which difference is constantly present, and impact what is sayable and thinkable, because they are connected to nested contexts and formations 
that are not always evident. Yet improvisations do occur in spite of their apparent impossibility. Discourses of purity and absolutist thought are themselves shown to be impossible by improvisatory reckonings and fashionings that allow for accident, risk, and improbable outcomes.

But more than that, these sites that engage our desire to know otherness, that model diversity, that gather forces of resilience into enduring constructs, are, pace Cornelius Cardew (described by Eddie Prévost as "composer turned improviser"), "the collective 'searching for sounds and the responses that attach to them' as a way of practicing to be a human being" (Prévost 279; our emphasis).

There is no one way forward in this, no reductive scheme that can encompass the kind of listening-making Cardew and Prévost aspire to, the kind of seeking after sonic dialogues of call and response that proliferate. Inherent in this perspective is the ethos of engaging with otherness as a form of heuristic knowing, what Randy Fertel calls the "longing for unmediated experience" (169), wherein improvisation is a determinative force. ${ }^{4}$

\title{
VII
}

\begin{abstract}
Northeastern Brazil is known for the richness of its different rhythms and musical styles. Every poetic genre has its own unwritten rules and rhyme schemes. Historically, many Maracatu performers distanced themselves from a genre called coco by adapting their improvisational expression to the more professional style of cantoría de viola. Maracatu Rural is unique in that it has integrated and adapted both styles.
\end{abstract}

Many Maracatu poets also improvise in other styles. For my research, the coco de embolada, where two coquistas try to best each other in a poetic competition, is of great interest. Both singers perform their improvised verses over a typical coco rhythm played on pandeiro (tambourine). Coquistas entertain the audience by attacking their rivals orally through rapid rhythmic and thematic exchanges. - Stefan Weghuber

Derrida, in The Beast and the Sovereign Volume II, speaks of survivance as "that 'gestural, verbal, written, or other trace' entrusted 'to the sur-vival in which the opposition of the living and the dead loses and must lose all pertinence' ... Every artifactual trace, every living being, is a living-dead machine, a dead body buried in material institutions and yet resuscitated each time anew by 'a breath of living reading' . . Finitude, from its very first trace, is thus the work of the 'archive as survivance'-this archive with which we both begin and began” (qtd. in Iveson 104).

Improvisation is critical to the archive--it foreshadows its possibility in the context of the specific genealogies that give rise to it while also providing creative, principled additions to it and how it is read: "The very concept of improvisation verges upon reading, since what we often understand by improvisation is the creation of something new, yet something which doesn't exclude the pre-written framework that makes it possible" (Derrida 322).

According to Weghuber, "Maracatu singers mostly draw upon two kinds of poetic resources: memorized verses called balaio or decoração and improvised lines known as improvisado or feito na hora. Every poet depends on a variety of set phrases and prepared rhymes as insurance against awkward pauses during performance (Travassos 10), and some write their most important lines down in a caderno (small booklet). According to Mestre Barachinha, a performer has three culturally acceptable options: to improvise freely; to chant internalized lines; or to combine these two elements (Veloso and Basílio 49)."

Weghuber's insights into Maracatu show that the continuum of context, the genealogy of circumstances, impact the "something new" produced in an improvisatory moment always contingent on precedent realities-and something new that is particularly memorable and deemed worth repeating becomes part of an archive.

As with the Carnatic solkattu $u^{5}$ rhythm system, predicated on speaking syllables associated with percussion sounds that link phrases within meters (talas), global sites of improvisation often align with specific linguistic circumstances, the sound and play of a language, as a source of interplay with other forms of sounding. These connected musical and linguistic realities that ground improvisatory play of various sorts are highly distinctive, literally voiced in the specific sites in which they occur, with all the distinctive soundings that only those sites can produce. 
Orality and improvisatory utterances are bound together and traverse a highly evolved sonic language.

Coco de embolada, as Weghuber shows, is a form of improvisatory contest exceptionally dependent on a range of site specific factors: the nature of the instruments that accompany the words, the speakers' knowledge of tradition, the linguistic play possible only by speakers whose proficiency maps local knowledge and culture into improvised verses that address rivals.

In Cuba, repentismo is oral poetry sung in improvised décimas (ten-line stanzas)—declared in 2012 an intangible cultural heritage of the country at the International Cubadisco Music Awards Festival. According to writer and repentismo singer Alexis Díaz-Pimienta,

En Cuba, "repentismo," "punto cubano," o "punto guajiro," es como se le denomina al arte de la improvisación poética, un ejercicio de estilo agonal (canto amebeo) que se ha convertido con el tiempo en la más importante manifestación poética popular de la isla, fundamentalmente en ámbitos rurales.

A diferencia de otros países en los que se improvisa con distintas estrofas (cuartetas, quintillas, sextillas, octavillas, décimas), en Cuba la improvisación es monoestrófica: sólo se improvisan décimas y para su acompañamiento se usa el "punto", una forma musical en que se emplean básicamente instrumentos de cuerdas: laúd, tres y guitarra, acompañados por la clave y el güiro (aunque el güiro actualmente se usa menos).

[In Cuba, "repentismo," "punto cubano," or "punto guajiro" [predecessors to son style song derived from Andalucia] - this is how it is called the art of poetic improvisation-is an exercise in agonal style (amebeo song [literally Amoebaean singing]), which has become over time the most important popular poetic manifestation of the island, mainly in rural areas.

Unlike other countries that improvise with various stanzas (quatrains, quintains, sextets, octets, décimas), in Cuba the improvisation is monostrophic: they only improvise décimas and accompany them using the "punto," a musical form that employs stringed instruments: the laud, the tres and guitar, accompanied by claves and the guiro (although the guiro is currently used less).] (our translation)

Díaz-Pimienta's summary of the particular circumstances that typify this form of improvisation in Cuba show an extraordinary richness of different musical confluences: from Andalusian song through to ancient Greek pastoral (associated with Theocritus) competitive singing contests between shepherds; from the instrumental accompaniment of clave, tres, and guiro, each with very distinctive sounds and playing techniques; from the Cuban campesino rural circumstances that, too, have a distinctive history. Each of these factors produces a unique situatedness that animates the specifics of improvisatory form.

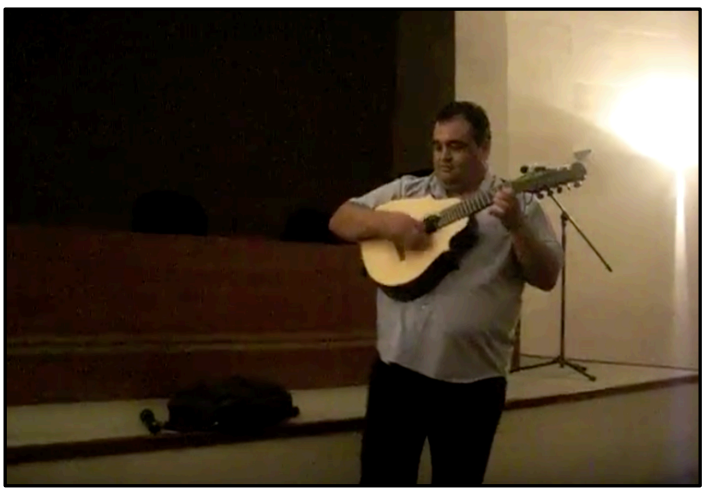

Click the image above to view an example of Desafío A. Díaz Pimienta y Yeray Rodríguez in performance.

As much as improvisation points to vast ecologies of knowledge, then, it also points to the epistemic possibilities yet to be realized from those ecologies. 
VIII

In the wake of Stalin's death East German jazz proponents countered the official reading of jazz as a propagandistic tool of imperialism consistent with the SED's [Socialist Unity Party] dissociation from Western capitalist culture by arguing that some forms of jazz and African-American music were in fact an authentic expression of the oppressed black working class and were therefore imbued with an oppositional potential regarding the anti-imperialist struggle. - Harald Kisiedu

We must beware of universalizing tropes of improvisatory resistance while remaining attentive to the ways sitespecific, identify-inflected, cultural-political paradigms do, in fact, travel and retain some of their meanings as they are performed and heard in new contexts.

What are the political and ethical stakes of embracing or rejecting such meanings? How are those who are not African American (white, neither/nor, both/and, "other") implicated when they make one of these choices about "jazz"?

It cuts complicated . . .

Ghanaian reed player and artist Nii Noi Nortey derives from the work of John Coltrane profound spiritual and social meaning and inspiration for his own music (much of which builds directly from Coltrane's), his self-made instruments, his sculpture, and his Anyaa Arts Library: a pan-African collection of books, recordings, and artifacts (Feld 87-118).

As she came of age in South Africa, "colored" vocalist Sathima Bea Benjamin was inspired politically and musically by Billie Holiday and her autobiography, Lady Sings the Blues. But Benjamin had a hard time establishing herself as a working artist in the United States in the 1960s, situated as she was between traveling paradigms. Too lightskinned and too much a jazz singer to be sufficiently and exotically African, she also lacked the anchoring authenticity of American-ness (and maleness) to be fully heard as a jazz musician (Kelley 153-54).

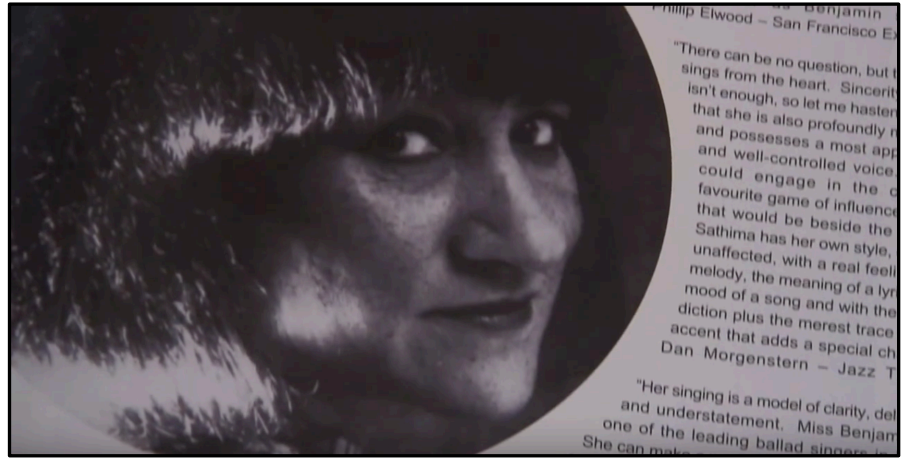

Click the image above to view the trailer for the film, Sathima's Windsong.

We embrace both artists as heroic, cosmopolitan figures.

When Yui Shōichi and other Japanese jazz critics sought to define a politicized, Japanese jazz in the late 1960s, they sometimes did so in dialogue with the ideas of Amiri Baraka (LeRoi Jones) and other Black, nationalist critics. "They found," as E. Taylor Atkins puts it, "confirmation of the propriety and rectitude of their quest in the increasingly politicized and racialized discourse on jazz in 1960s America" (Atkins 249), in the increasing discomfort with US cultural hegemony in the jazz world and with the United States' imperial presence in Japan and elsewhere in Asia.

According to Czech-Canadian writer Jozef Škvorecký, who experienced both Nazi and Soviet occupation, and totalitarian restrictions on jazz dance orchestras,

no matter what LeRoi Jones says to the contrary, the essence of this music, this 'way of making music,' is not simply protest. Its essence is something far more elemental: an élan vital, a forceful vitality, an explosive creative energy as breathtaking as that of any true art, that may be felt even in the saddest of blues. Its 
effect is cathartic. But of course, when the lives of individuals and communities are controlled by powers that themselves are uncontrolled-slavers, czars, führers, first secretaries, marshals, generals and generalissimos, ideologists of dictatorships at either end of the spectrum-then creative energy becomes a protest. ("Red Music" 124)

How do the specificities of place and history, the position of the choosers in wage-labor relations, in economies of gender and sexuality, in politically asymmetric relationships, shape the ethical, political, and analytical judgments we make about such engagements with traveling paradigms, with "the syncopations and the phrases, the scamp and the beat, the lyric and the melody"?

IX

Improvisation has always been at the heart of the laptop ensemble. Many
performances include novel logistical settings and collaborative forms,
technologies, and sonic structures. An emphasis on new instrument
design and a shared drive to innovate has opened the way for many new
modes of improvisation, including with DIY interfaces (Arduino open-
source software, for instance), through processing-rather than
generating-sound, and with loop-based material, among many others.
Navigating these unchartered territories demands rapid, creative
responses to emergent possibilities and challenges. - Eldad Tsabary

Technologies are nurtured by paradigms: the scientifically revolutionary, and those that overstay their welcome. Consider atomic weapons, coal-burning electrical plants, and antibiotics.

Cultural paradigms, both revolutionary and persistent, are nurtured by technologies, both emergent and residual.

What are the half-lives of inter-, trans-, and multiculturalism? Do these isms persist as long as the material and ideological technologies of coloniality? As long as recording technologies fix and mix difference across aural time and space?

Tsabary's work suggests that emergent forms of music force us to rethink the situatedness of improvised musical practices: "Presently, most laptop orchestras are Euro-American, but there are a growing number of ensembles forming in other regions, and some ensembles (like EO) are multi-local in nature with a geographically distributed membership. Whether multilocal or unilocal, laptop performances are typically alocal, and while there are many cultural, geographical, and human influences on performers, these influences too are varied, rapidly changing, and difficult to isolate or trace."

What work, if any, does alocal music do in the face of power? Does it map / affirm / refuse difference, as do the culturalisms we cherish (and fetishize)? How does alocal music sit in relation to coloniality, capitalism, racism, heteropatriarchy, and neoliberalism? To the migrant, the citizen, and the non-citizen? To, quite simply, who has a laptop and an Internet connection and who does not?

The alocal perceives and improvises a global population in asymmetrical flux.

Perhaps the alocal also insists on thinking power differently, from the inside out, as it maps transformative collaborations with, and interpellation by, circuits and chips and digital data.

Adam Scott Neal discusses "rule-based improvisation frameworks" and "computer interface design" as forms of composition, arguing, pace Arthur Danto, that "a composition is no longer limited simply to its sound or structure" (12). Improvisation as meta-composition, sound created with meta-instruments: technology brings new forms of local creative process into global telematic dialogue, thus generating alocal spaces and sounds. The Pacific Rim of Wire concert,

performed by SLOrk [Stanford Laptop Orchestra] . . . at Dinkelspiel Auditorium, Stanford University ... was an online concert with China, as part of the 2008 Pan-Asian Music Festival. In this first laptop orchestra telematic concert, musicians from SLOrk and the Stanford New Ensemble connected with musicians of Central Conservatory of China in Beijing to perform - in real time via networking - a program that celebrates 
music, technology, and international collaboration ... (Wang et al. $)^{6}$

Is improvisation always already a site of the alocal arising from the specific contingencies that make it possible? Improvisation, here, as a space of difference produced by new sound configurations: transformative cyborg shifts in time and place, a new iteration of improvisation as a socially situated practice in which novel forms of creative contact and community arise.

Is the alocal an imaginative topography that challenges normative constructions of the local? Improvisation as the space sound creates when dislocated from normative practice. Is the alocal the means by which national, state, federal, provincial, and other boundaries get re-imagined as a self-constituting community? How do new technologies that enable improvisation also re-imagine spatial realities that create new forms of identity?

What does it mean to simultaneously be and not be in a space where sound is the defining feature?

$\mathbf{X}$

Improvisation encompasses a wide range of practices worldwide, and aligning any of these with struggles for social justice depends not on generic formal characteristics of musical processes and products, but rather upon a contingent articulation of culturally-specific meanings by artists, professionals, and audience members invested in certain compelling narratives that structure musical experience in relation to their own needs for agency and empowerment. When various participants view the same musical practices as invested with different culturally specific meanings, any overarching narrative must be understood as a staged enactment of a shared ideal performed to evoke, represent, or symbolize a common theme (e.g. "new socially responsive forms of communitybuilding across national, cultural, and artistic boundaries").

In this regard, ethnomusicological concerns for reflexivity, especially the explicit recognition of how scholarly research paradigms shape the meanings of cultural practices under study, cannot but foreground how ICASP's own axiological commitments to "democratic, humane, and emancipatory" music making in cosmopolitan transatlantic contexts shape its interpretive perspective and semiotic impact on improvisational practices worldwide. - Scott Currie

Universals mean differently based on the specific contexts and contingent relations that localize us. But perhaps the universal that cuts across contingencies is the shared hubris of scripting the world we want, always while negotiating - via recognition, refusal, doubt, hope, and so on-the evidence that such a world may never materialize.

Such is the work of critique-and getting out of bed each morning.

This special issue is a scripting of others' scripting that engaged the ICASP/IICSI project and, more specifically, the hopes and doubts we raised in a call-for-papers a few years back. In that call, we worried the collective deployment of "improvisation" as a North-American centric, universalizing trope and desideratum that obscures the specificities of improvisational practices across the globe.

We hoped out loud that a collection of smart essays such as those that follow would take a small step toward rethinking assumptions about improvisation as a global practice:

And rethinking the very idea that improvisation is a global practice.

And rethinking the politics we imagine flow from site-specific improvisational practices, always already intercultural in a localized, unremarked sense, but sometimes in a self-conscious and prescriptive way too.

And rethinking the ways we narrate said practices that box them into a narrow political, social, and ethical functionality, even when we know better. 
Presumably, the special issue's contributors, in their engagements with the ICASP/IICSI project and with the call-forpapers, have also engaged their own doubts about and hopes for their subjects, be they people, places, movements, or sounds.

And presumably they engaged their own doubts about writing more generally, which is the engine of critique and, for many us, the thing that revitalizes our ongoing engagement with thinking critically.

We offer the above quotations from contributors' essays, our reflections on them, and a few extraneous thoughts as an introduction to what follows: not as a prescription for how to read the pieces that constitute this special issue, but as an invitation to consider a multiplicity of readings and comparisons.

We hope, as well, that this issue will help open up space for new paradigms and their constitutive refusals.

It might be hubris for us to call for the "shap[ing of] interpretive perspective and semiotic impact on improvisational practices worldwide," but we can hope. Musical improvisation is no monoculture, nor is it meant to be a dominant discourse reduced to academic cant. It is predicated on sonic diversity, multiple practices of engaging with aurality, and unexpected convergences that are unpredictable and endlessly contingent. Its specificity arises from differential understandings of what it means in practice and in theory.

And we must never forget that this musical practice that is also a social practice demands active agency in the creation of meaning, whether in idiomatic or non-idiomatic form. Listening and dialogue, radical departures from the familiar and minute variations within established form, tradition, and the event horizon of the possible--all contribute to improvisatory iterations that shape meaning as it arises in the play of the world.

Not all of these improvisational creations are happy collaborations. Not all of them result in transcultural apotheosis or epiphany. Not all of them produce memorable music. But they are all part of a process of engagement that asks that we continue to make things and play together, sometimes happily, sometimes not; sometimes with utterly unique iterations that present dramatic new possibilities, sometimes with tired reiterations of a paradigm that has ossified or is struggling for new voicings.

Improvisation as a creative social practice allows for the full spectrum of possibility, including failure, including notes that don't ostensibly belong, but that have found their way into a specific moment for any number of reasons, including uneasy tensions that accompany risk-taking and unprecedented encounters. In these senses, improvisation troubles easy aesthetic judgments, and more often than not asks that we set aside facile judgments within the normative aesthetic expectations that improvisation sets out to challenge or, at the very least, trouble.

Wadada Leo Smith once said that the world can only survive if "we, as humans become earth beings committed in our cultural and political aspects to a pan-world future." Encounters that produce engagement, disengagement, and re-engagement must be nurtured and devised. Transcommunal experiments in affiliation and commitment must be fostered, as John Brown Childs argues, via "commonly developed experience"-_precisely the space that improvisation potentiates via Childs's notion of "constructive disputing." Meaningful tensions, arising from difference, "[entail] deepening interpersonal relations" (63). Improvisation is not a panacea, nor is it a system so much as it is an immanent structure of encounter that releases latent creative contingencies. The contingent challenges us to engage, here and now, with what the moment might have to offer, with our contingent relation to the moment and its intricacies.

We thank our contributors for their insightful, provocative commentaries that we hope will take the ongoing discussions about critical studies in improvisation a small step further. And we thank the CSI/ECI editorial team for its conscientious, hard work on this special double issue. We thank you, the reader, for your careful listening.

And we thank Cedric J. Robinson for his life's work. As this special issue went into production, shortly after he passed on June 5, 2016, we humbly and respectfully remembered him as a guiding light--someone who took on the difficult work of analyzing the long developing aberrations of power and imagining a different world.

May the dialogue(s) continue. 


\section{Notes}

${ }^{1}$ The word derives from Scottish writer lain M. Banks's 1996 SF novel, Excession, in which an interstellar culture comes into contact with an alien artifact that is an OCP (Outside Context Problem) singularity-a once-in-acivilization moment of contact with something wholly outside known epistemes and realities.

${ }^{2}$ Derome's phrase puns on the large parade/street band project Fanfare Pourpour with which Derome is closely associated (and which plays a wild combination of improvised, traditional Québécois and hybridized compositions) and on the Suoni per il Popolo (sounds for the people) Festival in Montreal, founded in 2001 and associated with two specific venues: the Casa del Popolo and the Sala Rossa.

${ }^{3}$ Details of L'Année and more info on and thoughts by Derome can be found here: www.jeanderome.com/annee.

${ }^{4}$ Fertel's discussion of chaos theory in relation to improvisation is useful here: "Improvisations debunk received truths, received ways of expression, and received hierarchies. Like chaos science, improvisations would have us see more of life, not only what Reason can see, the categorical, but what comes to us through the visionary, the unconscious, or the intuitive" (177).

${ }^{5}$ A Tamil term meaning "words bound together" (Nelson 1).

${ }^{6}$ See SLOrk's website for a description of this and related performances: slork.stanford.edu/events/2008/rim-of-wire/.

\section{Works Cited}

"Ambiances Magnétiques." Wikipedia, 24 Jan. 2016, en.wikipedia.org/wiki/Ambiances_Magnétiques. Accessed 27 Apr. 2016.

Argyropoulou, Gigi, and Hypatia Vourlomis. "Resonances: A Dialogue between Hypatia Vourloumis and Gigi Argyropoulou." Performance Matters, Live Art Development Agency, 3 Oct. 2012, www.thisisperformancematters.co.uk/potentials-of-performance/words-and-images.post153.html. Accessed 29 Apr. 2016.

Atkins, E. Taylor. Blue Nippon: Authenticating Jazz in Japan. Duke UP, 2001.

Bailey, Derek. On the Edge: Improvisation in Music. Channel 4, 1992.

Banks, lain M. Excession. Orbit, 1996.

Childs, John Brown. Transcommunality: From the Politics of Conversion to the Ethics of Respect. Temple UP, 2003.

DeLanda, Manuel. A New Philosophy of Society: Assemblage Theory and Social Complexity. Continuum, 2006.

Derome, Jean. “Année Jean Derome.” jeanderome, April 2015, http://www.jeanderome.com/annee. Accessed 27 Apr. 2016.

Díaz-Pimienta, Alexis. "Cuba: entre la décima y el repentismo.” Del Blog de Díaz-Pimienta, 23 Aug. 2013, www.diazpimienta.com/cuba-entre-la-decima-y-el-repentismo/. Accessed 29 Apr. 2016.

Elliott, Larry. "Richest 62 people as wealthy as half of world's population, says Oxfam." The Guardian, 18 Jan. 2016 , www.theguardian.com/business/2016/jan/18/richest-62-billionaires-wealthy-half-world-population-combined. Accessed 27 Apr. 2016.

Feld, Steven. Jazz Cosmopolitanism in Accra: Five Musical Years in Ghana. Duke UP, 2012.

Fertel, Randy. A Taste for Chaos: The Art of Literary Improvisation. Spring Journal Books, 2015. 
Gould, J.J. “Josef Skvoercky on the Nazis' Control-Freak Hatred of Jazz.” The Atlantic, 3 Jan. 2012, www.theatlantic.com/entertainment/archive/2012/01/josef-skvorecky-on-the-nazis-control-freak-hatred-ofjazz/250837/. Accessed 27 Apr. 2016.

Graham-Harrison, Emma. “Amjad Sabri: Pakistani Sufi Singer Shot Dead in Karachi.” The Guardian, 23 June 2016 , www.theguardian.com/world/2016/jun/22/pakistani-sufi-singer-shot-dead-in-karachi?CMP=share_btn_link. Accessed 30 June 2016.

Hasan, Wafaa. "Orientalist Feminism and the Politics of Critical Dialogue Between Israeli and Palestinian Women." Diss. McMaster University, 2011.

Iveson, Richard. "Animals Living Death: Closing the Book of Derrida." Review of The Beast and the Sovereign, Volume I/ by Jacques Derrida, translated by Geoffrey Bennington. Parallax, vol. 18, 2012, pp. 102-106.

lyer, Vijay. "Theorizing Improvisation: syllabus." Facebook, 1 Oct. 2014, www.facebook.com/notes/vijayiyer/theorizing-improvisation-syllabus/10152437438968111/. Accessed 27 Apr. 2016.

Iyer, Vijay and Mike Ladd. Holding It Down: The Veterans' Dreams Project. Pi Recordings, 2012.

“Just 8 Men Own Same Wealth as Half the World" Oxfam International, 16 January 2017, www.oxfam.org/en/pressroom/pressreleases/2017-01-16/just-8-men-own-same-wealth-half-world. Accessed 12 May 2017.

Kelley, Robin D. G. Africa Speaks, America Answers: Modern Jazz in Revolutionary Times. Harvard UP, 2012.

Labelle, Brandon. Acoustic Territories: Sound Culture and Everyday Life. Continuum Books, 2010.

Landgraf, Edgar. Improvisation as Art: Conceptual Challenges, Historical Perspectives. Bloomsbury, 2014.

Molotch, Harvey. "Death on the Roof: Race and Bureaucratic Failure." Space and Culture, vol. 9, 2006, pp. 31-34.

Murphy, Timothy S., translator. "The Other's Language: Jacques Derrida Interviews Ornette Coleman." Genre, vol. 37, 2004, pp. 319-29.

Neal, Adam Scott. “The Continuum of Indeterminacy in Live Computer Music.” MA Thesis. Queen's University Belfast, 2008.

Nelson, David P. Solkattu Manual: An Introduction to the Rhythmic Language of South Indian Music. Wesleyan UP, 2008.

Prévost, Edwin. "Exploratoria / Exploratoria." Improvisation erforschen-improvisierend forschen: Beiträge zur Exploration musikalischer Improvisation / Researching Improvisation-Researching by Improvisation: Essays About the Exploration of Musical Improvisation, edited by Reinhard Gagel and Matthias Schwabe, Columbia UP, 2016, pp. 262-81.

Robinson, Cedric J. Black Marxism: The Making of the Black Radical Tradition. Zed Press, 1983.

---. Forgeries of Memory and Meaning: Blacks and the Regimes of Race in American Theater and Film before World War II. U of North Carolina P, 2007.

Rowe, Keith. "Keith Rowe 13 Questions." Prepared Guitar, Blogger, 19 Apr. 2014, preparedguitar.blogspot.ca/2014/04/keith-rowe-13-questions.html. Accessed 29 Apr. 2016.

---, perf. "Keith Rowe. Prepared Guitar." Youtube, 12 Jul. 2006, www.youtube.com/watch?v=HnUVpiFHhmM. Accessed 29 Apr. 2016.

Škvorecký, Jozef. "Red Music." Keeping Time: Readings in Jazz History, edited by Robert Walser, Oxford UP, 1998, pp. 123-29. 
Slingerland, Edward. Trying Not To Try: Ancient China, Modern Science, and the Power of Spontaneity. Broadway Books, 2014.

Smith, Wadada Leo. Notes (8 Pieces) Source a New World Music: Creative Music. 1973.

Vallières, Pierre. Nègres Blancs d'Amérique. Typo, 1994.

Wang, Ge, Nicholas Bryan, Jieun Oh, and Rob Hamilton. "Stanford Laptop Orchestra (SLOrk)." Proceedings of the International Computer Music Conference (ICMC 2009), Montréal, Canada, International Computer Music Association, 2009, hdl.handle.net/2027/spo.bbp2372.2009.114. Accessed 29 Apr. 2016.

Wilkinson, Alec. “Time Is A Ghost: Vijay lyer's Jazz Vision.” New Yorker, 1 Feb. 2016, p. 22. 